\title{
LITERATURA INFANTIL E QUESTÕES ÉTNICO-RACIAIS: POR UMA LITERATURA AFRO-BRASILEIRA EM SALA DE AULA ${ }^{1}$
}

\author{
Abraão Vitoriano de Sousa, E. M. E. I. E. F. Augusto Bernardino de Sousa (A.B.S.), \\ abraaovitoriano@hotmail.com
}

\begin{abstract}
RESUMO
A literatura infantil contribui consideravelmente para o desenvolvimento da competência leitora na escola, em razão de possibilitar ao aluno experiências culturais, estéticas e de cunho intelectual: a apresentar os mais variados assuntos, dentre esses: contextos pertinentes à diversidade e questões sociais. Salientamos, pois, como objetivo principal desse trabalho: apresentar a literatura afrobrasileira na escola, destacando sua importância para a formação de leitores nas séries iniciais. Assim sendo, realizamos uma pesquisa bibliográfica referendada em Coelho (2000); nas Diretrizes Curriculares Nacionais para a Educação das Relações Étnico-Raciais e para o Ensino de História e Cultura Afro-brasileira e Africana (2005) e em Silveira (2012). Em vista disso, buscamos refletir acerca das contribuições de algumas literárias para a problemática em voga, a citar: "Memória das Palavras" (BARBOSA, 2006); "Menina bonita do laço de fita" (MACHADO, 2011) e "O menino Nito" (ROSA, 2008). Consideramos que a leitura literária e as questões étnico-raciais necessitam (re)criar vínculos a partir de uma apreciação construtiva que evidenciam a ótica das diferenças e a valorização das identidades.
\end{abstract}

PALAVRAS-CHAVE: Literatura Infantil; Diversidade; Identidades.

\section{INTRODUÇÃO}

A literatura infantil, por muito tempo, voltou-se para a difusão dos clássicos europeus: "A Cinderela", "A Branca de Neve" e "Chapeuzinho Vermelho". A perspectiva da cultura negra, tradicionalmente, acontecia em momentos isolados ou de forma pouco representativa na escola.

É importante destacar que a educação para as relações étnico-raciais configura uma conquista recente, a partir da Lei 10.639/2003 com a obrigatoriedade do Ensino de História e Cultura Afro-Brasileira, o que permitiu uma nova abordagem para o ensino, discutindo estigmas históricos como a descriminação e o racismo, com a finalidade de oportunizar ao aluno um posicionamento crítico mediante tais assuntos. Daí a preocupação com a formação

${ }^{1} \mathrm{O}$ presente trabalho não contou com apoio financeiro de nenhuma natureza para sua realização.

Revista de Pesquisa Interdisciplinar, Cajazeiras, n. 2, suplementar, p. 844 - p.854, set. de 2017. 
dos profissionais que vão exercer as funções e orientação de crianças nos aspectos da construção do ser humanizado, respeitando as diferenças raciais.

Neste sentido, assinalamos como objetivo maior desse estudo: apresentar a literatura afro-brasileira na escola, destacando sua importância para a formação de leitores nas séries iniciais.

Consideramos a escola como um espaço sociocultural e institucional notável para o conhecimento da cultura. Para isso, as instituições devem se tornar um ambiente transformador do ser social, cultural, humanista, visando uma futura sociedade antirracismo. Um dos elementos indispensáveis para essa transformação consiste na leitura de obras literárias, as quais favorecem um relevante diálogo sobre representações e significados da cultura negra. Nesta premissa, abordaremos neste trabalho, os seguintes livros: "Memória das Palavras" (BARBOSA, 2006); "Menina bonita do laço de fita" (MACHADO, 2011) e "O menino Nito" (ROSA, 2008)

Em linhas menores, o tema em foco delineia uma perspectiva para a formação de leitores na qualidade do ser social, cultural e ético, e também para professores na condição de repensar suas práticas e compreender a importância da cultura afro-brasileira na escola.

\section{BREVE PANORAMA DA LITERATURA INFANTIL}

Somente a partir do século XVIII, na Idade Moderna, manifesta-se a Literatura Infantil, impulsionada pelo declínio do feudalismo e pela nova estrutura unifamiliar burguesa, preocupada com a privacidade e bem estar dos seus membros (ZILBERMAN, 1998)

Dentro desse contexto, aponta-se uma nova concepção: a infância. Entre os estudiosos da época destacou-se Jean Jacques Rousseau, revolucionário por considerar que:

[...] A infância não era apenas uma via de acesso, um período de preparação para a vida adulta, mas tinha valor em si mesmo. Defendia uma educação não orientada pelos adultos [...] ressaltava que a criança deveria aprender por meio da experiência, de atividades práticas, da observação, da livre movimentação, de formas diferentes de contato com a realidade. (OLIVEIRA, 2008, p. 63).

Apesar de uma criança ser concebida como indivíduo em pleno exercício de maturação e aprendizagem, também necessitava de uma "atenção especial" - era um ser Revista de Pesquisa Interdisciplinar, Cajazeiras, n. 2, suplementar, p. 844 - p.854, set. de 2017. 
inocente e frágil -, logo a noção de infância restringiu-se "ao zelo" e transmissão de normas e condutas por parte dos adultos.

Nesse panorama, a literatura infantil acompanha a "ótica" do momento, no intuito de educar moralmente a criança, ensinando hábitos e valores para a construção de um cidadão hábil a conviver no meio capitalista. Instruir, disciplinar, monitorar, punir - são as palavras de ordem. A escola tinha como encargo preparar a criança para o convívio com os adultos. Não é de admirar-se que as primeiras obras são de autoria de pedagogos e professores, um estilo doutrinário e conservador; daí se estende a crítica, se realmente existiu a "literatura" como fenômeno de fruição e transcendência que ela representa. (ZILBERMAN, 1998, p. 16).

Um considerável avanço sobreveio no início do século XX, com as abordagens da psicologia experimental, cujo enfoque centrava-se nos estágios do desenvolvimento infantil. Discussões importantes, que contribuíram para caracterizar esse público, listar suas capacidades e necessidades, corroborando para uma nova perspectiva da literatura para crianças, passando a se incomodar com o diálogo/adequação entre o autor e o leitor (COELHO, 2000).

No mesmo século, nasce a literatura infantil-juvenil brasileira, com algumas publicações de autores consagrados, como Olavo Bilac (Contos pátrios, 1904); Coelho Neto (Através do Brasil) e os volumes de Monteiro Lobato. No entanto, em sua grande maioria constituía-se de traduções de clássicos e obras de apelo comercial. Nesse período, na produção poética ainda prevalecia à intenção didática.

Segundo Nelly Novaes Coelho (2000, p. 224), a poesia infantil brasileira "surge comprometida com a tarefa educativa da escola, no sentido de contribuir para formar no aluno o futuro cidadão e o indivíduo de bons sentimentos".

Isso justifica a inspiração romântica impressa nos poemas, os excessos na linguagem: no uso dos diminutivos, nos clichês poéticos. Pra mais fácil absorção: a recitação obrigatória, que exigia do aluno memorização, rigor no ritmo e na pronúncia.

Por este e outros motivos já elencados, a literatura infantil durante muitas décadas, designou um gênero literário menor, caracterizado pelos fins utilitário-pedagógico e moralizante.

De certo, o auge da literatura infantil ocorreu na segunda metade do século $\mathrm{XX}$, especificamente na década de 70. Simpósios, seminários e congressos encarregaram-se de 
estudar e debater acerca das carências e defasagens do tema, cujo propósito elucidava a leitura e literatura como um agente de formação da mentalidade, capaz de contribuir para o desenvolvimento do indivíduo em todos os seus sentidos.

Em virtude disso, transcorreu um significativo progresso no setor editorial, e a escola começa a preocupar-se pelo trabalho com a literatura infantil. Notavelmente, programas e campanhas do governo contribuíram para difundir a leitura e escrita, viabilizando coleções e volumes às instituições de ensino do país.

O legado de toda essa mobilização sublinha-se além da produção e consumo, uma vez que, colocou em pauta a estrutura interna do livro infantil, discutindo sobre os enredos, o lúdico, os personagens, e a representação da criança no texto e a comunicação entre esta e o autor.

Perante esse olhar, o autor e poeta Elias José (2009) enuncia:

A literatura pode nos levar a um mundo idealizado, capaz de nos dar, sem nos alienar, o que o cotidiano nos nega. A literatura pode nos levar a conhecer pessoas, as personagens de ficção, que geram em nosso espírito simpatia ou antipatia, e possibilitam que o nosso "eu" se encontre e se reconheça ou se estranhe em diferentes "eus". Este processo de identificação ou de projeção já nos dá a medida psicológica do texto literário, que age categoricamente sobre o caminho que nos leva à difícil viagem ao nosso interior. Saímos de um conto ou romance tontos de prazer e cheios de perguntas sobre o mundo e as pessoas que nos cercam. Sobre o mundo que somos nós e que, muitas vezes, desconhecemos. (JOSÉ, 2009, p. 19).

Atentando para esses aspectos, desdobra-se a literatura infantil contemporânea que "visa alertar ou transformar a consciência crítica do seu leitor/receptor" (COELHO, 2000, p. 29). Assim, vêm sendo publicadas obras infantis em diversas linguagens e formatos, empregando o humor, a narrativa; tentando acompanhar as exigências do leitor/criança, dono de outro perfil: "questionador" e com acesso deliberado às mídias da informação.

\section{POR UMA LITERATURA AFRO-BRASILEIRA EM SALA DE AULA}

Notavelmente, apesar de todos os avanços, a literatura infantil e a cultura afrobrasileira ainda encontram um grande abismo, estando ambas em um constante processo de diálogo e reconstrução. Na maioria dos personagens tradicionalmente apresentados, o negro nunca é referenciado, são sempre personagens excluídos socialmente. 
A crítica literária Dalcastagné (2011) assevera que:

São poucos os autores negros e poucos, também, os personagens - uma ampla pesquisa com romances das principais editoras do país publicados a partir de 1965 identificou quase $80 \%$ de personagens brancas, proporção que aumenta quando se isolam protagonistas ou narradores. Isso sugere uma outra ausência, desta vez temática, em nossa literatura: o racismo. Se é possível encontrar, aqui e ali, a reprodução paródica do discurso racista, com intenção crítica, ficam de fora a opressão cotidiana das populações negras e as barreiras que a discriminação impõe trajetórias de vida. (DALCASTAGNÉ, 2011, p. 309).

É preciso entender que na literatura infantil: a criança não tem uma "ligação afetiva real" dentro da criação da história, pois a esta é criada por um adulto, que usa da normalidade, sem esclarecer e presar a personagem negra, deixando-a submissa e sem vida. Toda essa situação gera padrões que muitas vezes limitam a participação da criança negra dentro, não só da literatura, mas da sua vida social.

Nesse contexto, Soares (1999) explicita:

Adequada seria aquela escolarização que conduzisse eficazmente às práticas de leitura literária que ocorre no contexto social e as atitudes e valores próprios do ideal de leitor que se quer formar; inadequada é aquela escolarização que deturpa, falsifica, distorce a literatura, afastando, e não as aproximando o aluno das práticas de leitura literária, desenvolvendo nele resistência ou aversão ao livro e ao ler. (SOARES, 1999, p. 47).

A lei 10.639/03 surge para mudar a restrição da literatura para crianças e a negritude, pois através dela tentam romper estereótipos quando se trata de personagens negras. Essa lei determina a obrigatoriedade do ensino de História da África em todo currículo escolar, o que proporciona uma grande mudança, uma vez que as crianças podem conhecer personagens negros e passar a ter outra visão no que se refere à importância e a contribuição de um povo que muito colaborou para formação social brasileira, além de desmistificar um futuro com menos preconceitos.

Neste cenário, podemos citar a criação do projeto "A cor da cultura", fruto de uma parceria entre o Canal Futura, a Petrobras, o CIDAN - Centro de Informação e Documentação do Artista Negro, o MEC, a Fundação Palmares, a TV Globo e a SEPPIR - Secretaria de políticas de promoção da igualdade racial; com a intenção de ampliar a visão de toda área educacional, no tocante à valorização da cultura afro-brasileira. Parte do projeto, o dicionário 
"Memória das Palavras" (2006), foi disponibilizado para as escolas do Brasil, e tem a apresentação de Rogério Andrade Barbosa (2006), o qual elucida:

O Brasil é a nação que tem a segunda maior população negra do planeta. País multicultural traz a marca indelével dos africanos e de seus descendentes em sua formação. Em nosso vocabulário, muitas das palavras usadas no dia-a-dia têm origem nos falares herdados da mãe-África, procedentes de diferentes grupos étnico-linguísticos, como os iorubás e, especialmente, os povos bantos. Pois não existe apenas uma, mas várias Áfricas, espalhadas num vasto continente, composto, hoje, de 53 países. Segundo um provérbio da Guiné-Bissau: A ORELHA VAI À ESCOLA TODOS OS DIAS. Basta, portanto, ter ouvidos e sensibilidade para perceber essas influências. Algumas palavras conservam seu sentido original, e muitas outras, dependendo da região e das comunidades, ganharam novos significados. Como a língua é uma expressão viva de cultura, ela é dinâmica. E outros vocábulos poderão surgir. (BARBOSA, 2006, p. 5).

Podemos mencionar essa obra como uma excelente oportunidade de aproximação e reconhecimento da criança para com a cultura africana. $\mathrm{O}$ significado das palavras, presentes no livro, evocam muita singeleza e encantamento. Cabe citar alguns verbetes:

Afroxé: Dança, semelhante a um cortejo real, que desfila durante o carnaval e em cerimônias religiosas.

Erê: Divindade ligada à infância. Criança, em iorubá.

Leva-se uma rapadura ao fogo, derretendo-a em água fervente. Coa-se e deixa-se no fogo para pegar o ponto. Depois, joga-se um pouco de canela em pó na mistura. Em seguida, mexe-se tudo e pulveriza-se com gengibre. Espalhe o conteúdo numa tábua amanteigada e corta-se em pedacinhos.

Ritumba: Tambor. No Pará, há uma dança de São Benedito chamada retumbão. (BRANDÃO, 2006, p. 6-35).

Vale salientar que a "negritude" foi essencialmente um movimento literário nos seus primórdios, oriundo de um sentimento de frustração dos intelectuais africanos e antilhanos de língua francesa, que não se sentiam representados pela cultura ocidental de matriz eurocêntrica. Então, o movimento manifestou-se enquanto protesto contra a atitude do branco, perante atitudes desprezíveis destinadas a originalidade da cultura negra. (BRASIL, 2005).

Assim, houve desde tempos mais remotos, um ato de recusa à assimilação colonial, e simultaneamente, uma defesa dos valores raciais do mundo negro.

O negro ganhou um significado, passou a ter mais orgulho da sua cultura, deixando a margem de si próprio, complexo de inferioridade. A valorização do povo negro foi uma proposta ideológica do movimento negro brasileiro, que passou a discutir e difundir os 
valores da cultura e estética negra, até mesmo, chegou a realizar um trabalho mais estruturado e reforçado, o que culminou na elevação da autoestima dos afrodescendentes.

De acordo com Nelly Novaes Coelho (2000), há dois modelos quanto à formação de valores empreendidas na literatura infantil, a citar: "o modelo tradicional", que visa uma concepção baseada no racismo; e "o modelo construção de uma nova mentalidade", fundamentado no antirracismo que, segundo a autora, na literatura para crianças " [...] essa luta já está bem evidente, [...] mesclam-se, em pé de igualdade, personagens de várias raças e também é abordado frontalmente o problema do racismo, considerando como uma das grandes injustiças humanas e sociais" (COELHO, 2000, p. 27).

Em conformidade com esse ponto de vista, Silveira (2012) ilustra que a produção de livros, sobre a temática em foco, divide-se em duas perspectivas: a primeira, diz respeito ao enaltecimento da tradição cultural dos países africanos através das narrativas lendárias; a segunda ocupa-se em tentar reverter à histórica invisibilidade da etnia negra através do protagonismo dos personagens.

Neste sentido, convém sinalizar a importância de duas obras como ponto de partida para a discussão étnico-racial nas primeiras séries.

Do ponto de vista de reconhecimento ou valorização da negritude, podemos citar o clássico de Ana Maria Machado (2011), o qual conta a história de um coelhinho branco que quer ter uma filha linda como sua vizinha: pretinha e bela, seus olhos assemelhavam-se a duas azeitonas pretas, seus cabelos enroladinhos a fiapos da noite e sua pele, escura e lustrosa, aos pelos da pantera negra. (MACHADO, 2011).

Em "Menina bonita do laço de fita", temos uma trama que expõe a beleza negra, com leveza, singeleza e humor. Tanto a mãe da menina, como a própria personagem, sente orgulho de suas origens africanas e o coelhinho entra no enredo para reafirmar isso, como nesta passagem:

"Por isso, daí a alguns dias ele voltou lá na casa da menina e perguntou outra vez:

- Menina bonita do laço de fita, qual é teu segredo pra ser tão pretinha?

A menina não sabia e já ia inventando outra coisa, uma história de feijoada, quando a mãe dela, que era uma mulata linda e risonha, resolveu se meter e disse:

- Artes de uma avó preta que ela tinha..." 
(MACHADO, 2011, p. 15).

Em outra dimensão, a autora Sonia Rosa escreve "O menino Nito", narrativa que conta a história de Nito, um menino que chorava por tudo, até que seu pai resolve intervir: “- Nito, meu filho, você está virando um rapazinho... Já está na hora de parar de chorar à toa. E tem mais: homem que é homem não chora. Você é macho." (ROSA, 2008). Acontece que o menino passa a trancar os choros e adoce por isso. O doutor é convocado e, após uma conversa com o menino, sugere que esse "desachore" os choros engolidos. Pai e filho percebem, então, que chorar faz parte e até os torna mais homens.

Para Silveira (2012), além da quebra de estereótipos quanto à masculinidade,

A questão étnico-racial não emerge como problema; sua presença se dá na narrativa imagética - a família e até o médico são representados como negros, sem que haja qualquer referência no texto verbal. Essa obra se insere em tendência bastante recente na literatura brasileira segundo a qual as personagens negras são inseridas em tramas cujos principais conflitos são de outra natureza, não sendo focalizadas diretamente situações de discriminação. Tal tendência buscar reverter a tradicional invisibilidade das personagens negras (quando não descritas verbalmente pela referência étnica) e a escolho do branco como "representante da espécie humana". (SILVEIRA, 2012, p. 187).

É necessário, então, conforme os PCNs (1997), que o aluno das séries iniciais conheça diferentes obras sobre a negritude conforme atividades livres e programadas pelo professor, que deve dispor de um planejamento em virtude das peculiaridades e composição escrita do texto literário, voltando-se para a invenção da linguagem, para as subjetividades e sensações, para a leitura de plurissignificações pelo discente, ser em formação do pensamento estético e crítico da realidade social que o rodeia.

\section{CONSIDERAÇÕES FINAIS}

O resultado dos estudos realizados no decorrer desse trabalho explicita um cenário de debates e tomada de consciência pertinente à importância de se considerar as questões étnicoraciais para além de um conteúdo, mas como um reconhecimento e vivência da diversidade a partir da leitura literária.

Consideramos, então, urgente que a escola repense seu papel na formação de leitores e avalie a literatura infantil como peça-chave para a discussão de temas fundamentais, a 
exemplo das relações étnico-raciais; não como a postura utilitário-pedagógica, utilizada nos momentos de consolidação do gênero literário para crianças e, sim, como um espaço de leituras e debates, um espaço de desmistificação e afirmação da diversidade pela literariedade que o texto convoca.

Compreendemos que a luta e as conquistas sociais do negro na sociedade brasileira referem-se a um processo histórico, no qual a literatura infantil pode contribuir consideravelmente, uma vez que por meio dela a criança vislumbrará novos horizontes e terá um desenvolvimento intelectual e social que leve em conta o negro a partir de suas singularidades e não como um personagem estigmatizado pela predominância de uma cultura eurocêntrica. As duas histórias mencionadas, "Menina bonita do laço de fita" e "Menino Nito", são exemplos de como a leitura literária na escola pode oportunizar ao aluno a capacidade de aprender e, neste ínterim, respeitar a cultura afro, que também é nossa cultura. É neste sentido de sensibilização e pertencimento que a abordagem da literatura infantil deve acontecer em sala de aula.

A concepção de diversidade cultural pode, sim, ser trabalhada em sala de aula, e através dela, o educador pode preparar as novas gerações para um mundo sem preconceito racial ou de qualquer outro gênero, possibilitando as crianças, a oportunidade de serem críticos e capazes de viver em sociedade, de maneira harmoniosa, e ativamente. 


\section{REFERÊNCIAS}

BRANDÃO, Ana Paula (coord.). Memória das Palavras. Apresentação de Rogério Andrade Barbosa. Rio de Janeiro: Fundação Roberto Marinho, 2006.

BRASIL. Diretrizes Curriculares Nacionais para a Educação das Relações Étnico-Raciais e para o Ensino de História e Cultura Afro-Brasileiras e Africanas. Brasília, 2004: Conselho Nacional de Educação.

BRASIL. Presidência da República. Lei no 10.639 , de 9 de janeiro de 2003. Altera a Lei ${ }^{\circ}$ 9.394, de 20 de dezembro de 1996, que estabelece as diretrizes e bases da educação nacional, para incluir no currículo oficial da rede de ensino a obrigatoriedade da temática "História e Cultura Afro-Brasileira".

BRASIL. Ministério da Educação. Diretrizes Nacionais Gerais da Educação Básica. Brasília: MEC, SEB, DIECEI, 2013.

BRASIL. Secretaria de Educação Fundamental. Parâmetros curriculares nacionais: introdução aos parâmetros curriculares nacionais / Secretaria de Educação Fundamental. Brasília: MEC/SEF, 1997.

COELHO, Nelly Novaes. Literatura Infantil: teoria, análise, didática. São Paulo: Moderna, 2000 .

DALCASTAGNÉ, Regina. A personagem negra na literatura brasileira contemporânea. In: DUARTE, Eduardo de Assis; FONSECA, Maria Nazareth Soares (Orgs.). Literatura e afrodescendência no Brasil: antologia crítica. Belo Horizonte: Editora UFMG, 2011. Vol. 4: História, teoria, polêmica, p. 309-337.

JOSÉ, Elias. Literatura infantil: ler, contar e encantar crianças. Porto Alegre: Mediação, 2009.

MACHADO, Ana Maria. Menina bonita do laço de fita. Ilustração de Claudius. 9. ed. São Paulo: Ática, 2011.

OLIVEIRA, Zilma Ramos de. Educação Infantil: fundamentos e métodos. $4^{\mathrm{a} e d}$. - São Paulo: Cortez, 2008.

ROSA, Sonia. O menino Nito: então, homem chora ou não? Ilustrações Victor Tavares. 4. ed. Rio de Janeiro: Pallas, 2008.

SILVEIRA, Rosa Hessel et al. A diferença na literatura infantil: narrativas e leituras. São Paulo: Moderna, 2012. 
SOARES, Carlos E. L. A negregada instituição: os capoeiras na Corte Imperial. Rio de Janeiro: Access, 1999.

ZILBERMAN, Regina. A literatura infantil na escola. São Paulo: Global, 1998. 